\title{
Accessibility, Usage of Reproductive Health Information and Attitude towards Reproductive Health Practices of Female Adolescents with Hearing Impairment in Lagos and Oyo States, Nigeria
}

\author{
Oyewumi, Adebomi ${ }^{1}$, Adigun Olufemi ${ }^{2}$ \\ '(Department of Special Education, Faculty of Education, University of Ibadan, Nigeria) \\ ${ }^{2}$ (Department of Special Education, Faculty of Education, University of Ibadan, Nigeria)
}

\begin{abstract}
The study investigated the accessibility and usability of reproductive health information and the attitude of female adolescents with hearing impairment towards reproductive health practices. A survey research design and multistage sampling procedure was employed to select 155 female adolescents with hearing impaired in Oyo and Lagos state respectively. Two research questions and two hypotheses were generated for the study. Data were collected through a structured questionnaire with a reliability coefficient of 0.71. Communication barrier, cost, and resources and negative societal attitude were found to influence accessibility and usability of reproductive health information by female adolescents with hearing impairment also; accessibility of reproductive health information has significant relative influence on the attitude towards reproductive health practices. The composite effect of accessibility and usability of reproductive health information was found to be significant with attitude towards reproductive health practice of female adolescents with hearing impairment. The study therefore concluded that access to and usage of reproductive health information could lead to healthy reproductive lifestyle. Based on the findings, female adolescents with hearing impairment should be given equal access to adequate reproductive health information and professionals should make concerted effort to develop a positive attitude towards persons with special needs.
\end{abstract}

Keywords- Accessibility, hearing impairment, information, usage, reproductive health

\section{Introduction}

Information is an essential commodity in all spheres of human development. It is the data and knowledge that intelligent systems (human and artificial) use to support decision making [25]. Decision about staying healthy is one of the greatest made by individual irrespective of status. The state of one's health largely determines individual's ability to meet life challenges and function optimally. This requires one's makeup, that is, mental, physical and biochemical to maintain a healthy level of functioning positive reproductive health status. [1] asserts that the human development from birth to adulthood is divided into three stages; childhood, adolescence and the adulthood with each stage having its own peculiar characteristics which differentiates it from the others. Out of these stages, the adolescence period is the most noticeable because of the dramatic changes in the physical structure and mental ability [2]. It is a period of rapid physical and emotional change characterized by stresses and tension as the child strives to establish independence and adulthood. [3] observes that adolescence is a transition time and includes an important biological, social, emotional and cognitive change that takes place quite rapidly over a relatively short period of profound changes and, occasionally turmoil.

The physiological and reproductive revolution of adolescents associated with puberty such as rapid body growth and sexual maturity forces the young adults to question "all sameness and continuities which were relied on and to refight many earlier battles". According to [1] the internal pressure associated with the pubertal stage gives rise to the development of sexual maturation. Sexuality and reproductive health practices of adolescents with and without hearing impairments have been a major challenge faced by parents, teachers, health care providers and other related stakeholders. This young individual with hearing impairment are increasingly exposed to inaccurate or incomplete information about reproductive health issues such as sex, HIV/AIDS and other sexually transmitted infections (STIs), teenage pregnancy, abortion, contraceptive usage, female genital mutilation and so on.

Generally, due to lack of adequate information, female adolescents with hearing impairment are exposed to various health risks which include sexually transmitted infections, unplanned pregnancies, unsafe abortion and untimely death as a result of complication emanating from Virginal Visico Festibular (VVF). Communication which involves information exchange is a vital activity which is central to a meaningful reproductive health practices. Observably, this is readily or provided for persons with hearing loss. Notably, hearing impairment imposes some limitation on the individual involved as the condition disorganizes the whole 
personality of the affected person, his/her physical, mental, social and psychological well-being [26]. They are also found to lag behind their hearing counterparts in cognitive development and reproductive health information. This effect is so pervasive as to affect not only the body and psychic nature of the individuals with hearing impairment but it includes the social and environmental awareness.

Reproductive health behaviour depends largely on societal constrictions and level of cultural permissiveness which dictates the mode of reproductive health practices. While biological determinants may have strong influence on individuals' sexual behaviour, the agents of socialisation such as family, peers, religious institutions and the mass media have powerful repressive effects on it [27] [1]. Failure to provide adequate and correct information on sexual health issues encourages them to seek information from other sources such as peers, mass media, pornographic films and the Internet [4]. Currently, radio, television and friends and relatives constitute great sources of information about reproductive health, each of this source serves the various group of women and girls who live in the same community differently.

Sexually active adolescents face significant risk for sexually transmitted infections, including HIV [5]. Rates of most common STIs including chlamydia and gonorrhea peak in late adolescence and early adulthood, with 15 to 24 years olds accounting for nearly half of all new STIs, including HIV diagnosed annually. Young females are disproportionally affected by these patterns of STIs. However, [6] and [7] affirm that early and regular access to reproductive health care and information including contraceptive counselling, STI testing and treatment, cervical cancer screening, and other preventive care approaches are key to assuring that early sexual behaviour does not result in negative outcomes. [28] in [7] opines that adult family member, tend to shy away from given access to reproductive health information and actively educating adolescents who are deaf about issues relating to sexuality.

[9] notes that most of the reproductive health programmes in developing countries have tended to focus on access to reproductive health and health facilities. The assumption is that provision and availability of reproductive health will help the adoption of healthy reproductive lifestyles among adolescents with or without disability. According to [10], provision of family planning methods has significant effect on choice of family planning and has enabled men to play positive roles in reproductive health while [11] argues that access to and use of accurate reproductive health information will assist communities that are targeted to make informed choices, central to responsible sexual and reproductive lifestyle. [12] remarks that access to school and higher education, youth programmes and training are critical if young individuals are to acquire self-efficacy. Access to and use of health information, knowledge about diseases, about bodily conditions and functions are evident determinants of health status and outcomes [13]. As informant (Learning to know) is only useful if reinforced by positive attitudes (Learning to be) and useful skills (Learning to do), the ability to recognize a potential problem, must be accompanied by the will and the identification of the means necessary to avoid it.

According to [14] and [29], the responsibility of parents is to give sexual information to their offspring about personal, physical and social aspects of sexuality, pregnancy, sex roles and sex-related matters, including STD prevention and management. This responsibility is a major concern in most societies and can be considered an obligation in many traditions. [15] observes that in some cultures, parents and family members are influential source of knowledge, beliefs, attitudes and values for children and youth. By ensuring access to reproductive health information, [30] point out that children develop and practice responsible sexual behaviour and personal decision making. Yet in almost all societies, educating children about reproductive health is not a task that parents and other family members find easy, [17] notes that disabled adolescents are frequently excluded from social activities, limiting their opportunities to learn, set boundaries and, ultimately, lowering their sense of selfworth. [18] asserts that knowledge gained from reading books and reproductive health information on media about sex, contraceptives and related issues tend to help female adolescents to avoid unwanted pregnancies and other risky reproductive health practices. [19] observes that religious traditions, values and cultures are essential sociological and psychological phenomena that play different role as risk and protective factor for reproductive health practices.

Effective communication is a fundamental challenge for women with special needs especially those with a hearing impairment[32] [33]. There is a severe deficit in the provision of formal health information for deaf [19]. Reproductive health classes may be sources of frustration and confusion for these women as well female adolescents with hearing impairment. Signed reproductive health classes are uncommon, so this excludes a large number of women who depend on sign language as their primary mode of communication. Deaf females encounter enormous challenges and discriminatory practices with respect to accessing pertinent information on reproductive health care [20] [21]. [21] estimated that 50 percent of female adolescents with hearing impairment experience difficulty when communicating with health professionals. Communicational and linguistic difficulties occur both at a personal level, as they interact with reproductive health professionals, and at an institutional level. [20] stated that health professionals fail to comprehend the uniqueness of the deaf culture and its associated linguistic identity. These challenges have the potential to exclude and marginalise females who are deaf from society. 
Female adolescents with hearing impairment face two main difficulties in getting reproductive health-related information. There is the absence of a standard sign language and teachers who are equipped with a specific reproductive health education curriculum for the hearing impaired adolescents that can be delivered through sign language. When interacting with health professionals, parents, peers, teachers and other family members, majority of hearing impaired females do not feel respected or supported [21]. [22] add to this area of research by proposing that cultural factors, sexual desire, media, biological factors, emotional factors, social cognitive factors, and environmental factors (peers and parents) influence reproductive health practice and sexual behaviour. [23] states that deaf patient often misunderstood health information; hence, they lack comprehension when such information is not presented in appropriate sign language.

[24] contends that personal characteristics social or interpersonal barriers; and environmental/situational barriers have a relationship with how an individual access and use health information. [31] notes that reproductive health behaviour largely depend on societal and the level of cultural permissiveness which dictate the mode of reproductive health practice. While biological determinants may have strong influence on individuals, reproductive behaviour, the agents of socialisation such as family, peers, religious institutions and mass media have powerful repressive effects on it. Moreover, the development of heterosexual behaviour during adolescence is natural and the development of a satisfactory sexual relationship is a significant milestone in the emotional life of the adolescents with hearing impairment. Therefore, this study will investigate the accessibility, usability of reproductive health information and their attitude towards reproductive health practice of female adolescents in Oyo and Lagos states.

\section{Objectives of the Study}

This study is to determine the accessibility, usability of reproductive health information and attitude towards reproductive health practices among female adolescents with hearing impairment. In addition, the study will establish the relationship between accessibility and usage of reproductive health information. The study will also determine the factors influencing access to the use of reproductive health information among female adolescents with hearing impairments both in Lagos and Oyo states, Nigeria.

\section{Research Questions}

The study attempts to answer the following questions:

* Does any relationship exist between accessibility as well as usage of health information and reproductive health practices?

* What are the factors influencing access towards the use of reproductive health information among female adolescents with hearing impairments?

\section{Hypotheses}

The following research hypotheses are posed for the study and it will be tested at $\mathrm{P}<0.05$ level of significance

1) There is no significant relative influence of accessibility and usage of reproductive health information on female adolescents with hearing impairment attitude towards reproductive health.

2) There is no composite influence of accessibility and usage of reproductive health information on female adolescents with hearing impairment attitude towards reproductive health practice.

\section{Research Methodology}

The descriptive research design was adopted for the study because it investigated the existing variables, access to reproductive health information, use of reproductive health information and attitude towards reproductive health practices of female adolescents with hearing impairment

\section{Participants}

The participants covered in the study are 155 in-school female adolescents with hearing impairment, in Lagos and Oyo states, Nigeria. The participants were selected through a multistage sampling technique which involves a purposive and simple random sampling technique to select female adolescents with hearing impairment in the two states.

\section{Instrumentation}

The instrument used for this study was a structured questionnaire developed by the researchers. The research instrument tagged "Reproductive Health Information Questionnaire (RHIQ)" is designed by the researchers to elicit information from participants about access to, use of reproductive health information and their attitudes to reproductive health practices. The reliability of the research instrument was determined using Cronbach Alpha and found to be reliable at 0.71 . 


\section{Method of Data Analysis}

The data obtained from the questionnaire were analysed using descriptive statistics of frequency count, simple percentages, mean and standard deviation and inferential statistics involving Pearson moment correlation analysis, analysis of variance, $\mathrm{t}$-test as well as multiple regressions.

\section{Presentation of Results}

Research Question 1: Does any relationship exist between access to and use of health information towards reproductive health practices?

Table 1: Relationship between access to and use of reproductive health information

\begin{tabular}{|lc|l|l|l|l|l|l|l|}
\hline & Variable & Mean $(\bar{X})$ & Std Dev & N & df & r & Sig & Remark \\
\hline \multirow{2}{*}{ Attitude } & Access to RHI & 29.361 & 7.039 & \multirow{2}{*}{155} & 153 & \multirow{2}{*}{0.48} & \multirow{2}{*}{0.55} & NS \\
& Use of RHI & 9.032 & 3.797 & & & & & \\
\hline
\end{tabular}

NB: RHI = Reproductive Health Information

RHP $=$ Reproductive health Practice

The table shows the relationship between access to and use of reproductive health information. The result from the table implies that there is no significant relationship between access to and use of reproductive health information to reproductive health practices $(r=0.48 ; p>0.05)$.

Research question 2: What are the factors influencing access towards the use of reproductive health information among female students with hearing impairments?

Table 2: Factors influencing access to and use of reproductive health information

\begin{tabular}{|c|c|c|c|c|c|c|c|}
\hline Items & $\mathbf{S A}$ & $\mathbf{A}$ & D & SD & $\frac{\text { Mean }}{\bar{X}}$ & StD & Position \\
\hline $\begin{array}{l}\text { My lack of ability to use my sense of } \\
\text { hearing prevents me from accessing } \\
\text { reproductive health information }\end{array}$ & $\begin{array}{l}21 \\
(13.5)\end{array}$ & $\begin{array}{l}59 \\
(38.1)\end{array}$ & $\begin{array}{l}69 \\
(44.5)\end{array}$ & $\begin{array}{l}6 \\
(3.9)\end{array}$ & 2.612 & 0.767 & $3^{\text {rd }}$ \\
\hline $\begin{array}{l}\text { It is forbidden by my parents to talk } \\
\text { about reproductive health issues at this } \\
\text { stage of mine }\end{array}$ & $\begin{array}{l}53 \\
(34.2)\end{array}$ & $15(9.7)$ & $\begin{array}{l}50 \\
(32.3)\end{array}$ & $\begin{array}{l}37 \\
(23.9)\end{array}$ & 2.541 & 1.191 & $4^{\text {th }}$ \\
\hline $\begin{array}{l}\text { People do not believe that special need } \\
\text { people should talk about reproductive } \\
\text { health matter }\end{array}$ & $\begin{array}{l}53 \\
(34.2)\end{array}$ & $\begin{array}{l}18 \\
(11.6)\end{array}$ & $\begin{array}{l}20 \\
(12.9)\end{array}$ & $\begin{array}{l}64 \\
(41.3)\end{array}$ & 2.387 & 1.326 & $8^{\text {th }}$ \\
\hline $\begin{array}{l}\text { My culture does not permit an open } \\
\text { discussion of sexual and reproductive } \\
\text { health matters }\end{array}$ & $\begin{array}{l}12 \\
(7.7)\end{array}$ & $\begin{array}{l}66 \\
(42.6)\end{array}$ & $\begin{array}{l}57 \\
(36.8)\end{array}$ & $\begin{array}{l}20 \\
(12.9)\end{array}$ & 2.451 & 0.813 & $5^{\text {th }}$ \\
\hline $\begin{array}{l}\text { People do not respect my reproductive } \\
\text { health and lifestyle }\end{array}$ & $\begin{array}{l}9 \\
(5.8)\end{array}$ & $\begin{array}{l}71 \\
(45.8)\end{array}$ & $\begin{array}{l}52 \\
(33.5)\end{array}$ & $\begin{array}{l}23 \\
(14.8)\end{array}$ & 2.425 & 0.813 & $6^{\text {th }}$ \\
\hline $\begin{array}{l}\text { Information about reproductive health is } \\
\text { not always available in sign language }\end{array}$ & $\begin{array}{l}20 \\
(12.9)\end{array}$ & $\begin{array}{l}45 \\
(29.0)\end{array}$ & $\begin{array}{l}70 \\
(45.2)\end{array}$ & $\begin{array}{ll}6 \\
(3.9)\end{array}$ & 2.329 & 1.051 & $9^{\text {th }}$ \\
\hline $\begin{array}{l}\text { I have problems with reproductive } \\
\text { health professionals because they lack } \\
\text { the ability to use sign language }\end{array}$ & $\begin{array}{l}43 \\
(27.7)\end{array}$ & $\begin{array}{l}52 \\
(33.5)\end{array}$ & $\begin{array}{l}57 \\
(36.8)\end{array}$ & $\begin{array}{l}3 \\
(1.9)\end{array}$ & 2.871 & 0.842 & $1^{\mathrm{st}}$ \\
\hline $\begin{array}{l}\text { I need to go with someone from the } \\
\text { hearing community who can translate } \\
\text { for me. }\end{array}$ & $\begin{array}{l}15 \\
(9.7)\end{array}$ & $\begin{array}{l}70 \\
(45.2)\end{array}$ & $\begin{array}{l}34 \\
(21.9)\end{array}$ & $\begin{array}{l}36 \\
(23.2)\end{array}$ & 2.412 & 0.952 & $7^{\text {th }}$ \\
\hline $\begin{array}{l}\text { The cost of health services prevents me } \\
\text { from seeking some services. }\end{array}$ & $\begin{array}{l}36 \\
(23.2)\end{array}$ & $\begin{array}{l}69 \\
(44.5)\end{array}$ & $\begin{array}{l}19 \\
(12.3)\end{array}$ & $\begin{array}{l}31 \\
(20.0)\end{array}$ & 2.709 & 1.038 & $2^{\text {nd }}$ \\
\hline $\begin{array}{l}\text { Lack of money, a browsing phone, } \\
\text { and/or a computer connected to the } \\
\text { Internet prevent me from getting } \\
\text { reproductive health information }\end{array}$ & $\begin{array}{l}25 \\
(16.1)\end{array}$ & $\begin{array}{l}37 \\
(23.9)\end{array}$ & $\begin{array}{l}57 \\
(36.8)\end{array}$ & $\begin{array}{l}36 \\
(23.2)\end{array}$ & 2.329 & 1.007 & $9^{\text {th }}$ \\
\hline
\end{tabular}

Note: Percentages are in parenthesis.

Table 2 above shows that the most influencing factor that inhibits access to and use of reproductive health information by the respondents is the inability of reproductive health professionals to use and understand sign language at $\bar{X}=2.871$. This is followed by the cost of health services at $\bar{X}=2.709$, inability to make use of the sense of hearing at $\bar{X}=2.612$. The table also reveals that parental attitude as well as cultural barriers influences access to and use of reproductive health information of females students with hearing impairment at 
$\bar{X}=2.541$ and 2.451 respectively. Lack of respect for the individual with hearing loss ( $\bar{X}=2.425$ ), and lack of money and other Internet enabled gadget $(\bar{X}=2.329)$ were found to influence accessibility and usage of reproductive health information among female students with hearing impairment.

\section{Testing the null hypotheses}

Research hypotheses 1: There is no significant relative influence of accessibility and usage of reproductive health information on the attitude of female students with hearing impairment to reproductive health practices.

Table 3: Relative influence of access to and use of reproductive health information on the attitude to reproductive health practices

\begin{tabular}{|l|l|l|l|l|l|}
\hline \multirow{2}{*}{ Model } & \multicolumn{2}{|l|}{$\begin{array}{l}\text { Unstandardized } \\
\text { Coefficients }\end{array}$} & $\begin{array}{l}\text { Standardized } \\
\text { Coefficients }\end{array}$ & T & \\
\cline { 2 - 4 } & B & Std. Error & Beta & & \\
\hline $\begin{array}{l}\text { Attitude towards } \\
\text { RHP }\end{array}$ & 13.100 & 1.055 & & 12.416 & .000 \\
\hline Access to RHI & -.302 & .031 & -.418 & -9.688 & .000 \\
\hline Use of RHI & 1.012 & .058 & .756 & 17.514 & .000 \\
\hline
\end{tabular}

NB: RHI = Reproductive Health Information

RHP $=$ Reproductive Health Practices

Table 3 shows that accessibility $(\beta=-.418, \mathrm{t}=-9.688, \mathrm{p}<0.05)$ and usage $(\beta=1.012, \mathrm{t}=17.514, \mathrm{p}<0.05)$ of reproductive health information has significant relative influence on the attitude towards reproductive health practices among female students with hearing impairment. This suggests that accessibility and usage of reproductive health information has a significant influence on the attitude of female students with hearing impairment towards reproductive health practices.

Research hypotheses 2: There is no significant composite effect of access to and use of reproductive health information on the attitude of female students with hearing impairment towards reproductive health practices.

Table 4: Composite effect of accessibility and usage of reproductive health information on the attitude towards reproductive health practices

\begin{tabular}{|l|l|l|l|l|l|}
\hline Model & Sum of Square & Df & Mean Square & F & Sig \\
\hline Regression & 2852.815 & 2 & 1426.407 & & \multirow{2}{*}{192.641} \\
\cline { 1 - 4 } $0.000^{\mathrm{a}}$ \\
\hline Residual & 1125.482 & 152 & 7.404 & & \\
\hline
\end{tabular}

$\mathrm{R}=.847^{\mathrm{a}}$

R Square $=.717$

Adjusted r square $=.713$

Std. Error of the Estimate $=2.72112$

Table 4 shows that there is a composite effect of access to and use of reproductive health information on the attitude of female students with hearing impairment towards reproductive health practices $(\mathrm{R}=0.717)$. Some 71.3 per cent of the variance accounts for the attitude of female students with hearing impairment towards reproductive health practices. The composite effect is also shown to be significant $\left(\mathrm{F}_{(2,152)}=192.641, \mathrm{P}<0.05\right)$.

\section{Discussion of Results}

Research question 1 finds no significant relationship exists between accessibility, use of reproductive health information and attitude towards reproductive health practices. This implies that accessibility, use of reproductive health information does not translate to having a positive attitude towards reproductive health practices. This result corroborates the findings of [6] [7] that early and regular access to reproductive health care and information including contraceptive counselling, STI testing and treatment, cervical cancer screening and other preventive cares are key to ensuring that early sexual behaviour does not result in negative outcome. [11] also asserts that accessibility and usage of accurate health information assist target communities make informed choices which are required for positive sexual and reproductive lifestyles. The finding negates the observation of [28] that adults worry about how much information and access to give to adolescents with hearing impairment about sexuality.

Research question 2 on what are the factors influencing access towards the use of reproductive health information among female students with hearing impairments? The result reveals that the most serious factors that inhibit accessibility and use of reproductive health information by respondents are communication problem and lack of financial capacity. The finding also shows that parental attitudes as well as cultural barriers 
influence accessibility and use of reproductive health information of female students with hearing impairment. The finding supports [6] that the culture of silence have reinforced negative and sometimes - confrontational attitudes among Nigerians towards information/education on sexual and reproductive health and rights, with devastating effects, especially on vulnerable groups such as adolescents, women, people with special hearing needs and sexual minorities. [19] [20] [22] [24] [31] also find that economic barrier and communication gap between healthcare provider and adolescents with hearing loss prevent full access to reproductive health information. The study is not consistent with the finding of [23] who stated that inability to comprehend reproductive health information through various medium is a major factor that prevents the adolescents with hearing impairment from obtaining adequate sexuality education.

Hypothesis 1: There is no significant relative influence of access to reproductive health information on the attitude of female students with hearing impairment towards reproductive health practices. The result shows that access to reproductive health information has significant relative influence on the attitude towards reproductive health practice among female students with hearing impairment. This implies that access to reproductive health information has a significant influence on the attitude of female students with hearing impairment towards reproductive health practices. The finding is in consonance with [11] [13] [30] on providing children giving access to health information which helps them develop and practice responsible sexual behaviour and take wellinformed personal decision and access accurate reproductive health information that will assist adolescents with special needs make informed choices, required and necessary for use of sexual and reproductive lifestyle.

Hypothesis 2 reveals that there is significant relationship between accessibility, use of reproductive health information and attitude towards reproductive health practices. This result conforms to the findings of [11] also asserts that accessibility and usage of accurate health information assist target communities make informed choices which are necessary and vital for positive sexual and reproductive lifestyles. The finding negates the observation of [8] [28] that adults worry about how much information and access to give to adolescents with hearing impairment about sexuality.

\section{Conclusion}

The study investigates accessibility and usability of reproductive health information and attitude towards reproductive health of female adolescents with hearing impairment. It found notes there is no significant relationship between access to, use of reproductive health information and attitude towards reproductive health practices of female adolescents with hearing impairment. The deficiency of reproductive health professionals in the use of and understand sign language, the hearing related problems of female adolescents with hearing impairment, parental attitude as well as cultural barriers are found to influence accessibility and the usability of reproductive health information by female adolescents with hearing impairment. Further, the study reveals that increase in the accessibility and usage of reproductive health information will lead to an increase in the attitude towards reproductive health practices among female adolescents with hearing impairment.

\section{Recommendations}

Consequent upon the study findings, it is recommended that female adolescents with hearing impairment should be accorded equal access to reproductive health information through free medical services for persons with hearing impairment. Information regarding various issues in reproductive health practices such as use of contraceptives, and HIV/AIDS should be reader friendly. Also, health care professionals should be trained on the use of sign language and/or sign language interpreters should be employed in medical centres for reproductive health needs of female adolescents to remove the communication problems of females with hearing impairment. The modalities of implementing reproductive health information programme should be reviewed and strengthened through the use of information communication technology, mobile phones via text messaging and branding to effectively reach adolescents with or without special needs and to reach out to other stakeholders.

\section{Journal Papers:}

\section{REFERENCES}

[1] F.O., Olaniyi, Towards improving adolescents sexual behavior and reproductive health. In Contemporary issues and researcher on adolescents. Nwazuoke, I.A, Yemisi, B and Moronkola, O.A. Eds. Network for Health and Welfare of Special People. Pp 215-221.

[2] I. F., Kost, J.D., Forrest and S., Harlap, Comparing the health risks and benefits of contraceptive choices. Family Planning Perspective, 18(2), 2001, 66-76.

[3] O.A. Moronkola, and A.O. Aremu, The challenges of adolescent in Nigeria: health education, promotion and counselling implications. In Contemporary issues and researchers on adolescents. Nwazuoke I.A; Yemisi, B and Moronkola, O.A. Eds. Network for Health, Education and Welfare of Special People. 2004, Pp 35-42.

[4] F.A. Okanlawon, Peer Education: An Effective tool for promoting positive change in Adolescents' Risky sexual behaviour. In Nwazuoke, I.A. Yemisi, B and Moronkola, O.A. (Ed.): Contemporary Issues and Researchers on Adolescents. Network for Health, Education and Welfare of Special People, 2004, Pp 153-161. 
[5] J.R. Lauren, and C. D. Brindis, Access to reproductive health care for adolescents: establishing healthy behaviours at a critical juncture in the life course. Current Opinion in Obstetrics and Gynecology, 22, 2010, 369-374.

[6] C. D Brindis, A public health success: understanding policy changes related to teen sexual activity and pregnancy. Annual Review of Public Health, 27(1), 2006, 277-295.

[7] A.O., Sangowawa, E.I., Owoaje, B., Faseru, T.P. Ebong, and B.J. Adekunle, Sexual practices of deaf and hearing secondary school adolescents in Ibadan, Nigeria. Annals of Ibadan Post-graduate Medicine, 7(1), 2009, 23-31

[8] I.E. Unuigbe, andO. Ogbeide, Sexual behaviour and perception of AIDS among adolescents girls in Benin City, Nigeria. African Journal of Reproductive Health, 3(1) 1999, 37:44.

[9] N.M. Thang, and D.N. Anh, Accessibility and use of contraceptives in Vietnam. International Family Planning Perspectives, 28(4), 2002, 214-219.

[10] H. Sherpa, and D. Rai, Safe motherhood: it is a family responsibility, reports on national safe motherhood awareness campaign. Safe Motherhood at the Family and Community, and Community Support Network, 1997, 73p.

[11] U.D. Upadhyay, Informed choice in family planning, helping people decide. John Hopkins School of Population Reports, Series J, 2001, No. 50 .

[12] A. Palmer, Residing youth worldwide, John Hopkins Centre for communication programmes, 1995-2000, Working, Paper No. 6 Baltimore, Maryland, Johns Hopkins University, Bloomberg School of public Health, April, 2002.

[13] E. Rogue, The convention on the rights of the child and rights to sexual reproductive health. EntreNous, 2001, No. 51. Copenhagen, WHO Regional Office for Europe.

[14] O.M. Odujinrin, Sexual activity, contraceptive practice and abortion among Obstertrics in Lagos, Nigeria. International Journal of Gynecology, and Obstetrics, 34(4), 1991, 361-366.

[15] B. Barnett, Gender norms affect adolescents. Network 17(3), 1997. 145-155

[16] N. Groce, Rape of individuals with disability: AIDS and the folk belief of "virgin cleansing". Lancet, 363, 2004 1663-1664.

[17] O. A. Okwilagwe, Bibliotherapeutic influence on Nigerian female university student: self report on sexual attitudes and behaviours. Nigerian Journal of Clinical and Counselling Psychology. 1(2), 1993, 173-186.

[18] Word Youth Report, The special concern for adolescents and youth. Youth and Health Issues, 2003.

[19] B. Josiah, Hearing the needs of deaf mother to be. The Practicing Midwife, 9 (3), 2004, 22-33.

[20] L.I., Iezzoni, B.L., O’Day, M. Killeen and H. Harker, Communicating about health care: observations from persons who are deaf and hard of hearing. Annals of Internal Medicine, 140(5), 2004, 356-62.

[21] E.J. Steinberg, Pushing for equality: deaf Irish mothers and maternity care. Deaf Studies Today, 2, $2006,249-291$.

[22] J. Brooks -Gunn and R.L., Paikoff, Promoting healthy behaviours in adolescence: the case of adolescent sexuality and pregnancy. Annals of the New York Academy of Medicine, 67(6), 1991, 527-547.

[23] J. Kelsall, She can lip read, she'll be all right: improving maternity care for the deaf and hearing impaired. Midwifery, 8, 1992, 198183.

[24] T.D. Wilson, Models in information behaviour research. Journal of Documentation, 55 (3), 1999, $249-270$.

\section{Books:}

[25] L.O. Aina, Library and information science text for Africa (Ibadan, Third World Information Services Ltd, 2004).

[26] P.O. Mba, Fundamental of special education and vocational rehabilitation (Ibadan, Codat publication, 1991).

[27] C.M. Anikweze, Sexuality in adolescence, In Adolescent psychology, Orji, A.S. and Arukweze, C.M. Eds (Ibadan, DE-Ayo Publishers, 1998).

[28] J.S. Alter, Teaching parents to be the primary sexuality educators of their children (Bethseda, MD: Mathtech INC, 1984).

[29] R. Blum, and P. Rinehart, Reducing the risk: connections that make a difference in the lives of youth (Minneapolis, University of Minnesota, 1998).

[30] S. Moore, and D. Rosenthal, Sexuality in Adolescence (London, Routledge, 1993).

[31] D. Crystal, The Cambridge encyclopedia (Cambridge, University of Cambridge Press. 1990).

[32] Royal National Institute for the Deaf, A simple cure: a national report into deaf and hard of hearing people's experiences of the national health services (London, Royal National Institute Deaf, 2004).

Proceedings Papers:

[33] L. Clark, Accessible health information: Liverpool central primary care trust. Project Report (Liverpool, Liverpool Centre Primary Care Trust, 2002) 